\title{
Synthesis and Characterization of New Polymer from Bisacodyl A
}

\section{Intisar Y. Mohammed*}

*Center of Petroleum Research, Directorate of Materials Research, Ministry of Science \& Technology, Baghdad, Iraq

**Department of Chemistry, College of Education Pure Sciences /Ibn AL-Haitham, University of Baghdad, Baghdad, Iraq

E-mail: nasorayouo@yahoo.com

Received 7/10/2015

Accepted 20/12/2015

(i) $\Theta \Theta$

This work is licensed under a Creative Commons Attribution-NonCommercial-

NoDerivatives 4.0 International Licens

\section{Abstract}

A new series polymers was synthesized from reaction starting material Bisacodyl A or [(2-Pyridinylmethylene) di-4, 1-phenylene di acetate] with hydrogen bromide, then the products were polymerized by addition polymerization from used adipoyl and glutaroyl chloride.

The structure of these compounds was characterized by FT-IR, melting points, TLC, X-Ray, DSC and ${ }^{1} \mathrm{H}-\mathrm{NMR}$ for starting material. These compounds were also screened for their antibacterial activists.

Key words: Bisacodyl A, Polymer, adipate, glutrate

\section{Introduction:}

Bisacodyl A or [(2-Pyridinylmethylene) di-4, 1-phenylene di acetate] is an organic compound that is used as a stimulant laxative drug. It works directly on the colon to produce a bowel movement. It is typically prescribed for relief of constipation and for the management of neurogenic bowel dyes function as well as part of bowel preparation before medical examinations, such as for a colonoscopy[1] .

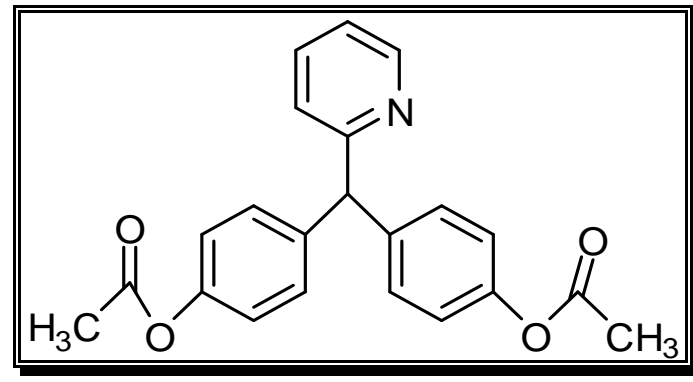

Fig. (1) (2-Pyridinyl methylene) di-4, 1 Phenylene diacetate [ Bisacodyl A]

Bisacodyl A is a derivative of di phenyl methane. It was first used as a laxative in 1953 due to its structural similarity to phenolphthalein $[2,3]$. When bisacodyl $\mathrm{A}$ is administered orally, it is usually taken at bedtime. 
Oral administration is known to produce no action for more than eight hours and then to work suddenly and relatively quickly. This is especially true if more than 10 milligrams is taken at once. Normally the dosage is 5 or 10 milligrams, but up to 30 milligrams can be taken for complete cleansing of the bowel before a procedure. If taken too early in the evening, the action of this drug can start during sleep with undesirable results. If taken at the maximum dosage, there will likely be a sudden, extremely powerful, uncontrollable bowel movement and so precautions should be taken. It is not recommended to take bisacodyl within one hour of taking an antacid or milk, as this may destroy the tablet coating and irritate the stomach. When administered rectally in suppository form, it is usually effective in 15 to 60 minutes. Two suppositories can be inserted at once if a very strong, purgative, enema-like result is needed. A few hours after the initial evacuation, there can be a secondary action which will continue as long as there is unexpelled bisacodyl A present in the rectum. As a small commercially prepared enema, it is usually effective in 5 to 20 minutes[4] .

\section{Mechanism of Action}

Bisacodyl A works by stimulating enteric nerves to cause colonic mass movements (contractions). It is also a contact laxative; it increases fluid and $\mathrm{NaCl}$ secretion, action of bisacodyl A on small intestine is negligible; stimulant laxatives mainly promote evacuation of the colon [4-6].

\section{Materials and Methods:}

Synthesis of 4, 4-(pyridin-2ylmethylene) di-4, 1-phenylene di carboxyl $[\mathbf{E}]^{[4]}$

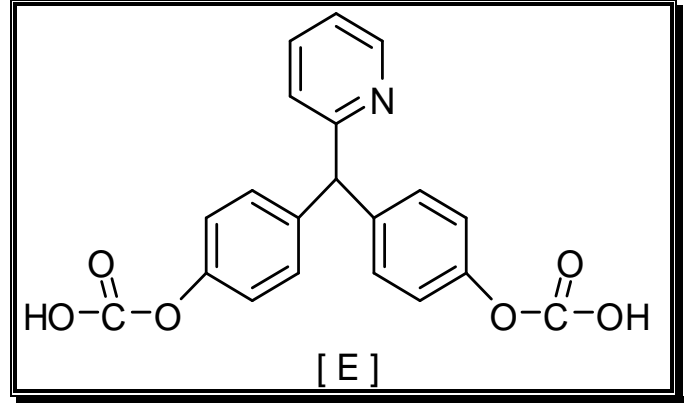

Fig. (2): 4, 4-(Pyridin-2-ylmethylene) di-4,1-phenylene di carboxyl [E]

A mixture of bisacodyl A (10.20gm, 1.00 mole) with hydrogen bromide $(0.10 \mathrm{~mol})$ was refluxed at $\left(120^{\circ} \mathrm{C}\right)$ for $24 \mathrm{hrs}$. Then the mixture was poured onto ice water bath, the product was extracted with ethyl acetate, washed with sodium carbonate, filtered to obtain gray gummy, yield (93\%).

Synthesis of poly (4-(4-(methoxy phenyl) (pyridine-2-yl) methyl) 6phenyl adipate $\left[\mathbf{E}_{\mathbf{a}}\right]^{[7]}$

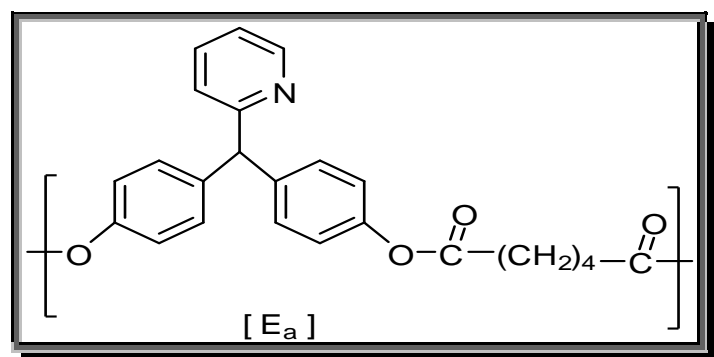

Fig. (3): poly (4-(4-(methoxy phenyl) (pyridine-2-yl) methyl) 6-phenyl adipate $\left[\mathrm{E}_{\mathrm{a}}\right]$

The prepared polymer $\left[\mathrm{E}_{\mathrm{a}}\right]$ was prepared by dissolving compound [E] (1.0gm) in cold dry pyridine, and adding drop wise the di acid chloride (0.01mole) and drop stirred for $24 \mathrm{hrs}$ in ice bath. Then the mixture was poured in crushed ice with 10\% HCL. The precipitate was filtered, dried and recrystallized by washing with ethanol to obtain solid crystals, m.p $\left(234^{\circ} \mathrm{C}\right)$.

Synthesis of poly (4-(4-(methoxy phenyl (pyridine-2-yl) methyl) 5phenyl glutrate $\left[\mathbf{E}_{b}\right]^{[7]}$ 


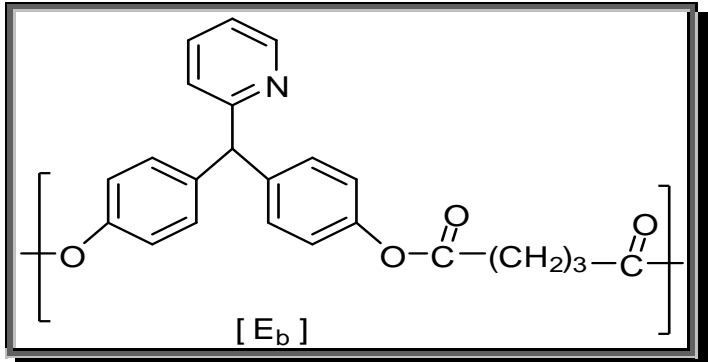

Fig. (4): poly (4-(4-(methoxy phenyl (pyridine-2-yl) methyl) 5-phenyl glutrate $\left[\mathbf{E}_{\mathbf{b}}\right]$

The prepared polymer $\left[\mathrm{E}_{\mathrm{b}}\right]$ was prepared by dissolving compound [E] $(1.16 \mathrm{gm})$ in cold dry pyridine, and adding drop wise the di acid chloride (0.01mole) and drop stirred for $24 \mathrm{hrs}$ in ice bath. Then the mixture was poured in crushed ice with 10\% HCL. The precipitate was filtered, dried and recrystallized by washing with ethanol to obtain solid crystals, m.p $\left(232^{\circ} \mathrm{C}\right)$.

\section{Results and Discussion:}

Preparation and Characterization of 4, 4-(pyridin-2-ylmethylene) di-4, 1phenylene di carboxyl [E]

The structure of the product assignment on its melting point and spectral FT.IR, ${ }^{1}$ H-NMR spectroscopy, and the purity of this compound were checked by T.L.C. technique.

FT-IR spectrum for compound [E] is a representative model shows the appearance of the characteristic carboncarbon double bond $(\mathrm{C}=\mathrm{C})$ at $(1595) \mathrm{cm}^{-}$ ${ }^{1}$ and absorption band $\left(3257 \mathrm{~cm}^{-1}\right)$ is due to the (-OH) stretching [8]. Figure (5). All characteristic bands of compound (E) are listed in Table (1).

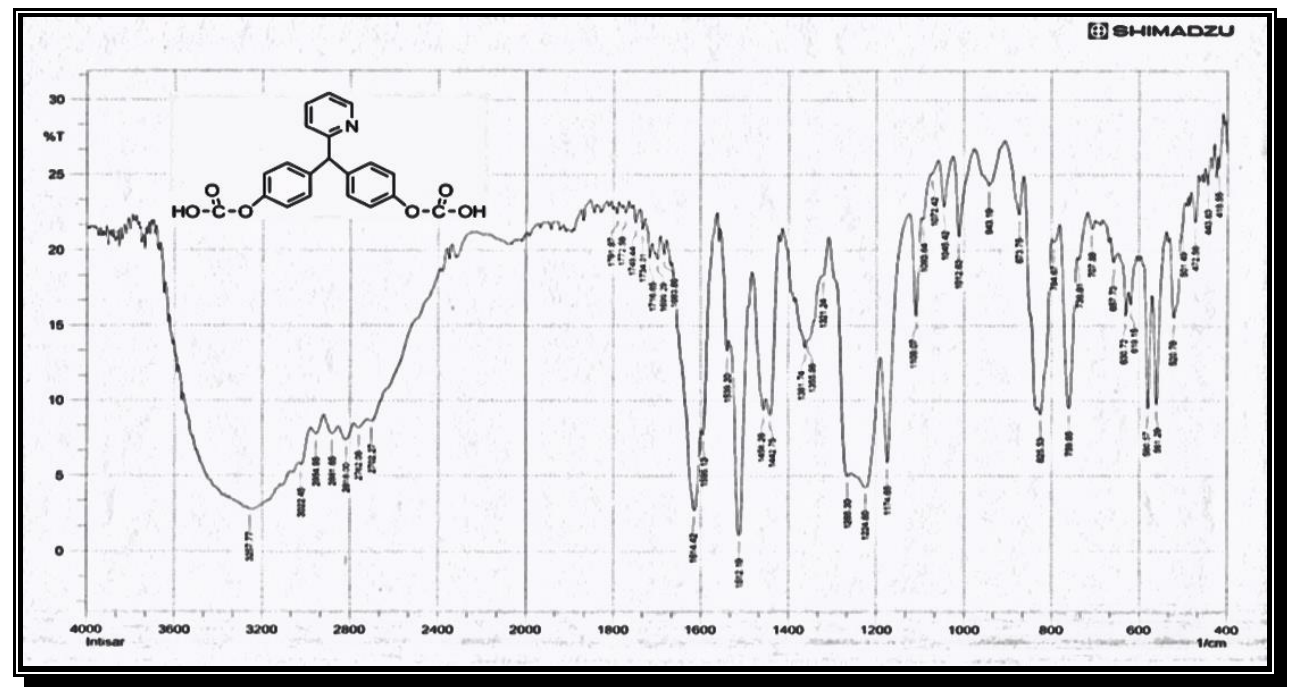

Fig. (5) FT-IR spectrum of compound [E]

${ }^{1} \mathrm{H}-\mathrm{NMR}$ spectrum of compound (E), Figures(6), shows the following characteristic chemical shifts $\delta(2.5 \mathrm{ppm})$ for (DMSO), the aromatic ring protons as multiple at $\delta(6.6-8.2) \mathrm{ppm}$, signal at $\delta(8.8-9.4)$ due to the $(\mathrm{C}-\mathrm{H})$ proton in pyridine ring, a signal appeared at $\delta$ (9.3) ppm (1H) of $(-\mathrm{OH})$. 


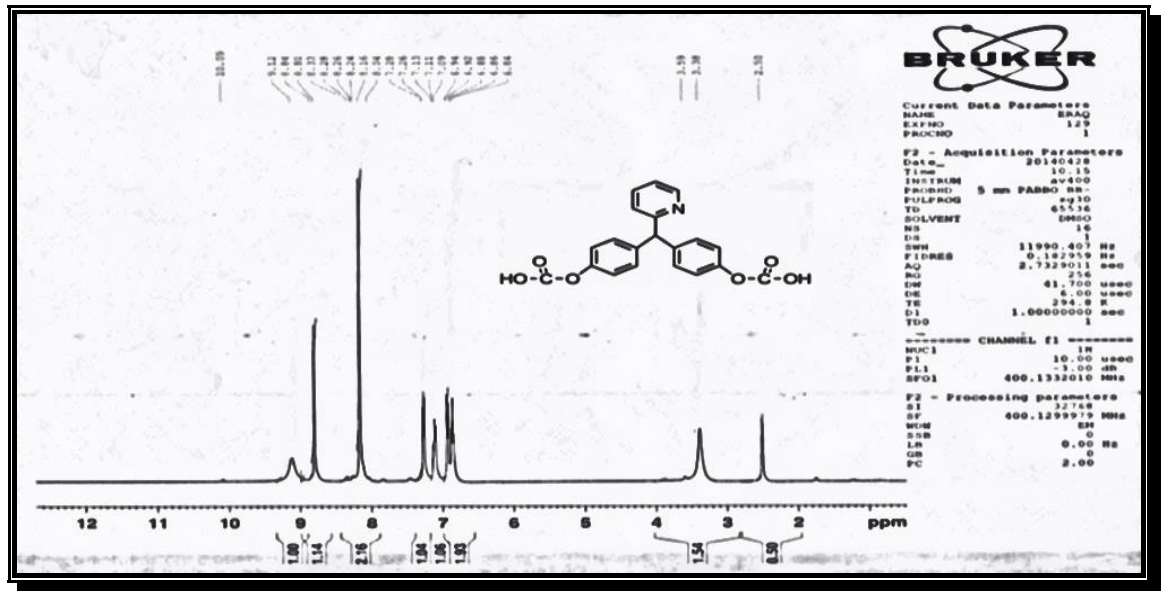

Fig. (6): ${ }^{1}$ HNMR spectrum of compound [E]

Preparation and characterization of *poly (3-(3-(methoxy carbonyl oxy) phenyl) (pyridine-2-yl) methyl) phenyl carbonic) 3- phenyl adipateanhydride *poly (3-(3-(methoxy carbonyl oxy) phenyl (pyridine-2-yl) methyl) phenyl carbonic) 4- phenyl glutrate
anhydride $\left[\mathrm{E}_{\mathrm{a}, \mathrm{b}}\right]^{[9]}$

These polymers were prepared from dissolving compound [E] in pyridine and reacted with adipoyl and glutaroyl chloride [10] as in the following equation $\backslash$

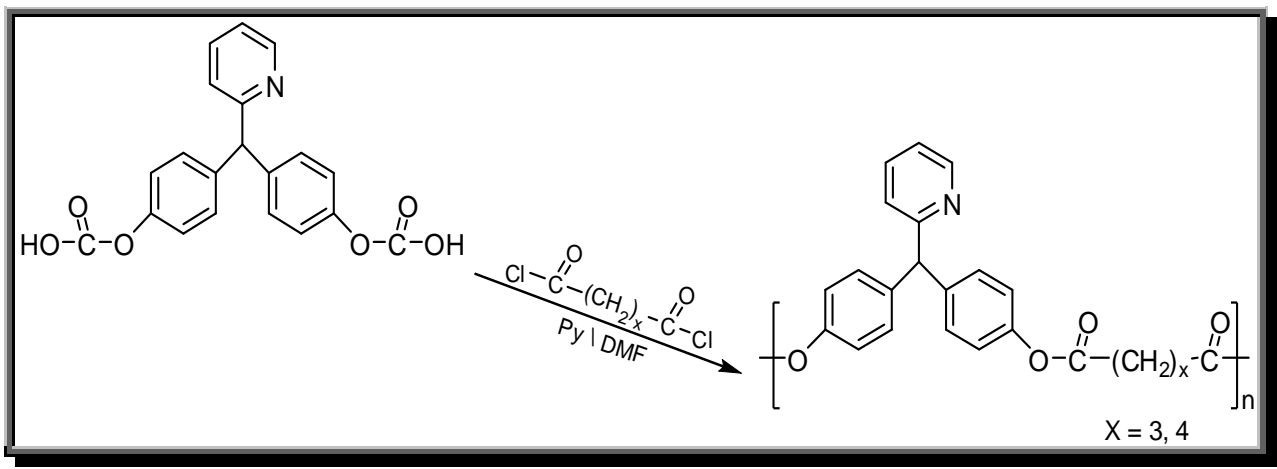

The FT.IR spectra of polymers [Ea, $\mathrm{E}_{\mathrm{b}}$ ], fig. $(7,8)$ showed the following bands at (1056) $\mathrm{cm}^{-1}$ due to $v(\mathrm{C}-\mathrm{O})$, at $(2935$, 2931) $\mathrm{cm}^{-1}$ for symmetric and

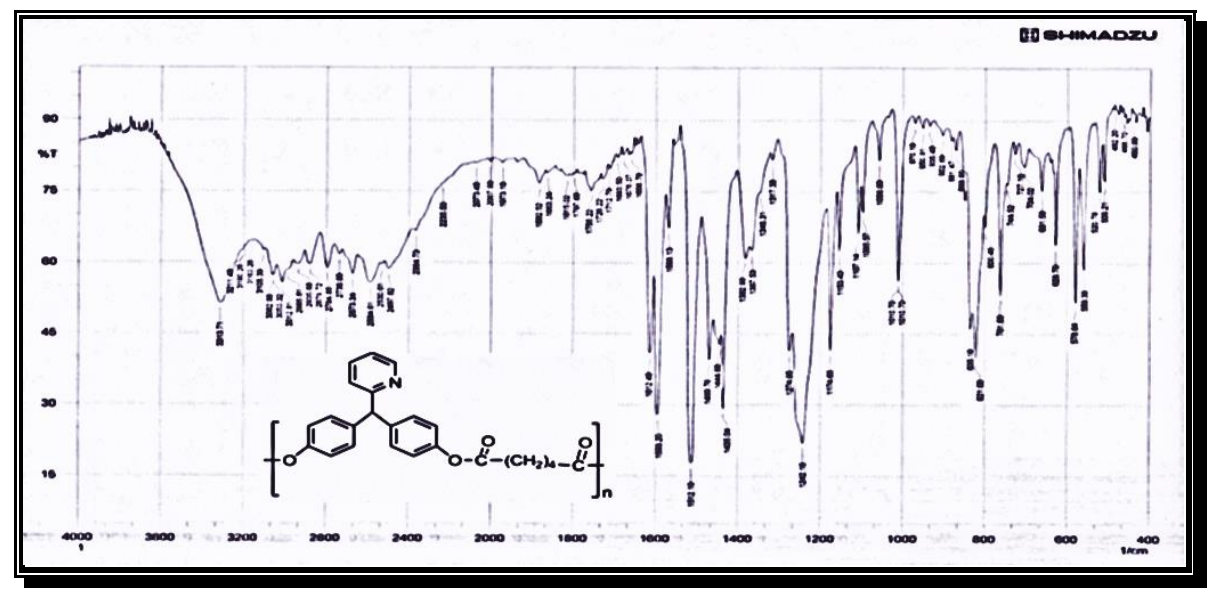

Fig. (7): FT-IR spectrum of compound [Ea] asymmetric stretching vibration of $(\mathrm{CH})$ aliphatic, at $(1759,1755) \mathrm{cm}^{-1}$ for $v$ $(\mathrm{C}=\mathrm{O})$. 
The $2^{\text {nd }}$ National Conference of Chemistry

Table (1) FT-IR spectral data of compounds [E, Ea, Eb]

\begin{tabular}{|c|c|c|c|c|c|c|}
\hline Com No. & $\begin{array}{c}v(\mathrm{C}-\mathrm{H}) \\
\text { aromatic } \\
\mathrm{cm}^{-1}\end{array}$ & $\begin{array}{c}v(\mathrm{C}-\mathrm{H}) \\
\underset{1}{\text { aliphatic } \mathrm{cm}^{-}}\end{array}$ & $v(C=\underset{1}{O}) \mathrm{cm}^{-}$ & $v(\mathrm{C}-\mathrm{N}) \mathrm{cm}^{-1}$ & $v(C=\underset{1}{N}) \mathrm{cm}^{-}$ & $\begin{array}{l}\text { Other bands } \\
\mathrm{cm}^{-1}\end{array}$ \\
\hline $\mathrm{E}$ & 3022 & 2954 & 1614 & 1361 & 1683 & $v(-\mathrm{OH}) 3257$ \\
\hline $\mathrm{E}_{\mathrm{a}}$ & 3014 & 29312879 & 1759 & 1367 & 1660 & $v(\mathrm{C}=\mathrm{C}) 1595$ \\
\hline $\mathrm{E}_{\mathrm{b}}$ & 3012 & 29352883 & 1755 & 1367 & 1660 & $v(C=C) 1595$ \\
\hline
\end{tabular}

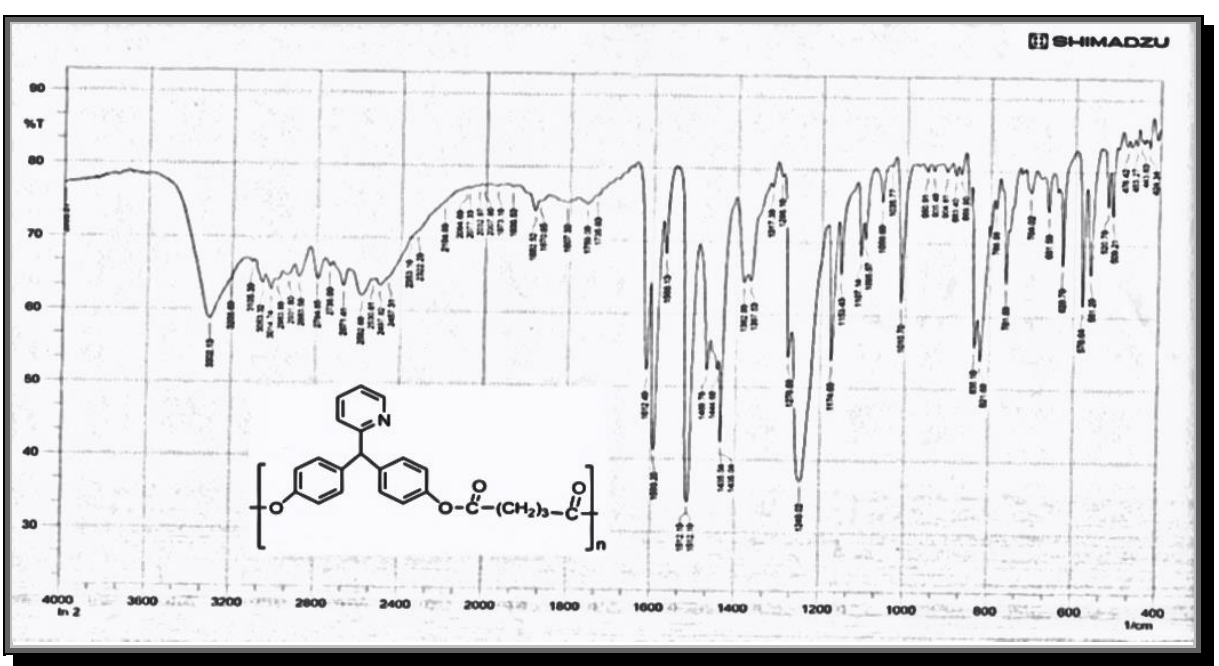

Fig. (8): FT-IR spectrum of compound [ $\left.\mathrm{E}_{\mathrm{b}}\right]$ Biologic activity ${ }^{[11]}$

Table (2) Biological activities of some of the synthesized compounds

\begin{tabular}{|c|c|c|c|}
\hline $\begin{array}{c}\text { Com } \\
\text { p No. }\end{array}$ & $\begin{array}{c}\text { E.Col } \\
\text { i }\end{array}$ & $\begin{array}{c}\text { Staphylococc } \\
\text { us }\end{array}$ & $\begin{array}{c}\text { Pseudomon } \\
\text { as }\end{array}$ \\
\hline $\mathrm{E}_{\mathrm{a}}$ & 14 & 12 & 15 \\
\hline $\mathrm{E}_{\mathrm{b}}$ & - & 10 & 16 \\
\hline
\end{tabular}

Key to symbols \ inactive (inhibition zone $<5 \mathrm{~mm}$ ); slightly active $+\quad$ (inhibition zone 5-10mm); moderately active ++ (inhibition zone 11 - 15mm); highly active +++ (inhibition zone >15mm)

\section{X-Ray diffractions}

$\mathrm{X}$-ray diffraction is also used to identify the nature of the polymers weather crystalline or amorphous. The $\left(\mathrm{E}_{\mathrm{b}}\right)$ are crystalline.

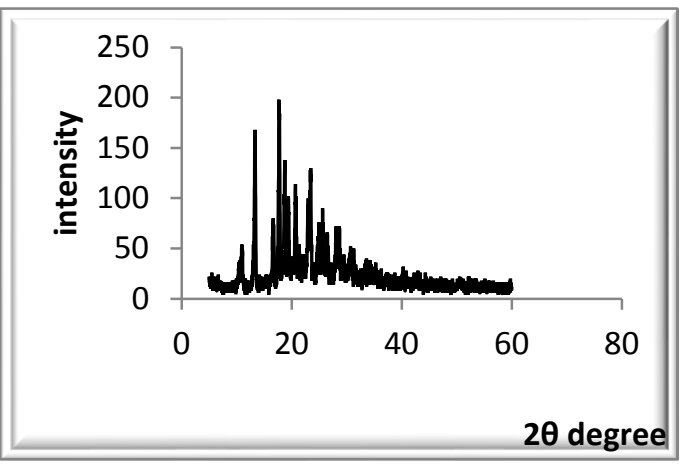

Fig. (9): X-Ray of polymer [Ea]

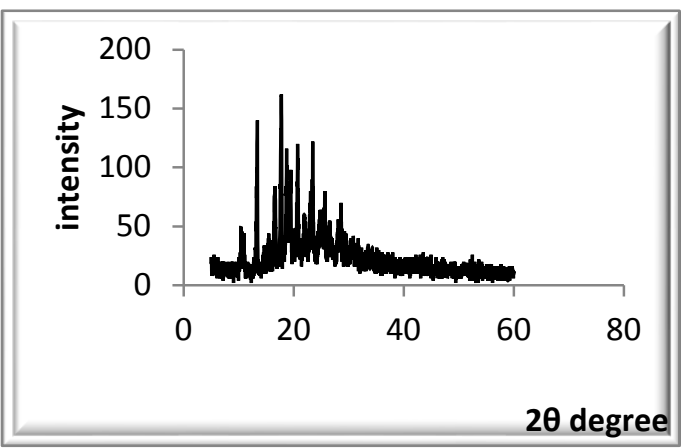

Fig. (10): X-Ray of polymer $\left[E_{b}\right]$

\section{Thermal Transitions}

A stack plot of DSC thermogram of depicted in figures (11-12).clear sole endothermic transition appeared at both 
plots represent the $\mathrm{Tg}$ of the products. The higher $\mathrm{Tg}$ value of these polymers can be assigned to the inter and intrainteractions hydrogen bonding that may be formed between the residual $\mathrm{N}-\mathrm{H}$ groups and other polar groups ${ }^{[12]}$. In Figure (11) for polymer $\left[E_{a}\right]$ Dec before melting that meaning thermally unstable, Figure (12) for polymer $\left[\mathrm{E}_{\mathrm{b}}\right]$ $\left(232^{\circ} \mathrm{C}\right)$ for m.p another dgree Dec.

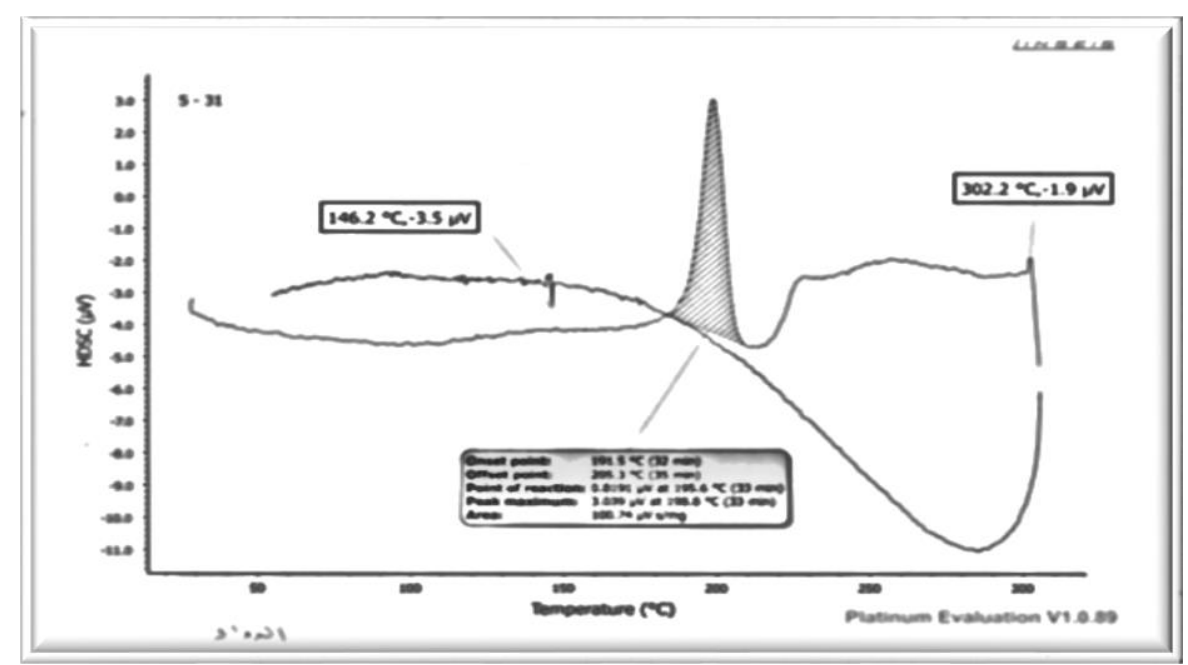

Fig. (11): DSC Thermogram of polymer [Ea]

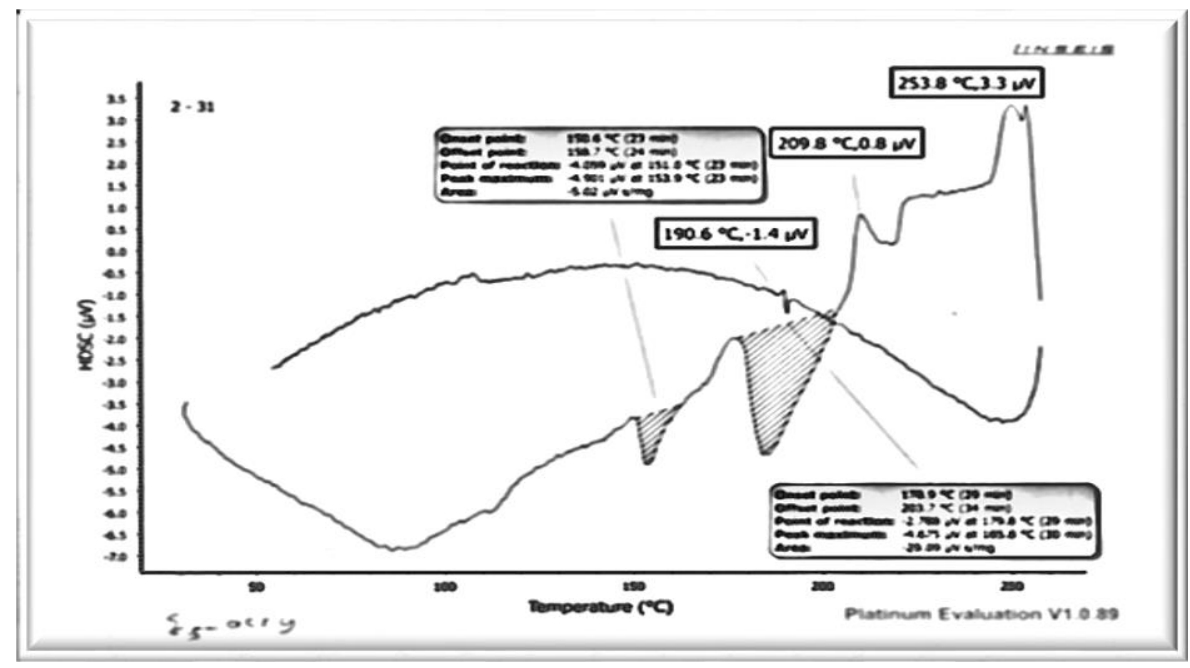

Fig. (12): DSC Thermogram of polymer $\left[E_{b}\right]$

\section{References:}

[1] American Society of Health-System Pharmacists, Medline Plus. June 2014., U.S. National Library of MedicinelU.S. Department of Health and Human Services National Institutes of Health $\backslash$ Inc. Disclaimer.

[2] Wexner, S. D.; Beck, D. E.; Baron, T. H.; Fanelli, R. D.; Hyman, N.; Shen, B. and Wasco, K. E. 2006. American Society of Colon and Rectal Surgeons; American Society for Gastrointestinal Endoscopy;
Society of American Gastrointestinal and Endoscopic Surgeons.

[3] Stiens, SA.; Luttrel, W.; and Binard, JE. (November 2009). Polyethylene glycol versus vegetable oil based bisacodyl suppositories to initiate side-lying bowel care: a clinical trial in persons with spinal cord injury. Spinal Cord 36 (11).

[4] Evans, I.; and Lynn. 1998, Methods and techniques: The use of Bisacodyl suppositories in preparation for 
sigmoidoscopy, B. Medical. [9] Umar. R. P. 2011. Synthetic Polymer J.,(5):271.

[5] Medicine: Cut out the Liver $\backslash 2010$. Time. 1951-04-16. Retrieved.

[6] Robert, E.; Erns,t S.; Wiley,VCH. Weinheim. and Jan, H. Zwaving. 2000. "Laxatives" in Ullman's Encyclopedia of Industrial Chemistry,

[7] Syam, S; Abdelwahab, SI; AlMamary, MA and Mohan, S. 2014. Synthesis of polymers with Anticancer Activities C. C. J. Molecules. 2012; 17(8) 6179-6195.

[8] Williams and Fleming, 1973, Spectroscopic Methods in Organic Chemistry. $2^{\text {nd }}(2)-61$.

Laboratory-II, Advances in Polymer Science and Technology an International. I. Journal, Department of Polymer Science \& Technology.

[10] Research on ethanol synthesis from syngas / 2015. Anomie theory. m.m/ view Paper [Synthesis of Tri phenyl methane derivative bisacodyl].

[11] Choosing Wisely; 2013. Five Things Physicians and Patients Should Question an initiative of the ABIM Foundation(A. A. of D.).

[12] Kevin, A. Wepasnick.; 2014. Anderson Materials Evaluation, ASTM E1356 - Standard Test Method for Glass Transition Temperatures by DSC.

\section{تحضير وتثخيص بوليمر جديد من البسكوديل أ}

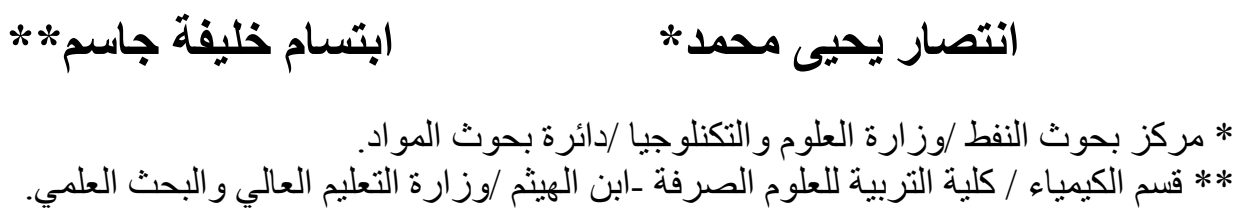

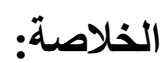

تم في هذا البحث تحضير بوليمرات جديدة وذللك من تفاعل المادة الاولية [" 2 بريدينيل مثلين" ثنائي 1,4 بلئي

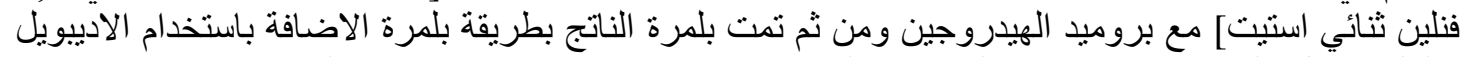

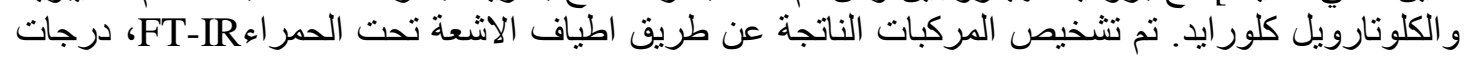

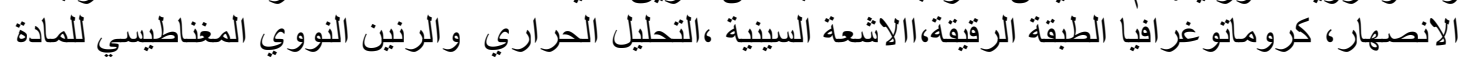

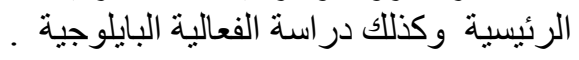

الكلمات المفتاحية : بسكوديل أ ، بوليمر، ادييوبل ، كلوترويل 